\title{
IMPACT OF COVID-19 OUTBREAK ON CLINICAL PRACTICE AND TRAINING OF YOUNG OTORHYNOLARYNGOLOGIST: A NATIONAL SURVEY.
}

\author{
Riccardo Morello ${ }^{1}$, Giacomo Bertazzoni ${ }^{1}$, Luca Pianta ${ }^{1}$, Milena Fior ${ }^{2}$, Giulia Berretti ${ }^{2}$, \\ Giovanni Marasco ${ }^{3}$, and Alberto Deganello ${ }^{2}$ \\ ${ }^{1}$ ASST Ospedale di Cremona \\ ${ }^{2}$ University of Brescia \\ ${ }^{3}$ Alma Mater Studiorum University of Bologna
}

May 14, 2020

\section{KEY POINTS}

- SARS-CoV-2 disease (COVID-19) is a major challenge for healthcare systems and physicians and may impact young otolaryngologists' training and clinical practice.

- The COVID-19 outbreak negatively influenced otolaryngologists' clinical activity and training in Italy.

- Interventions to evaluate and address residents' training gaps are needed.

- Online lectures represent a promising strategy to cope with the current situation while laying the foundations of a structured high-quality national teaching curriculum.

- A lack of training on the use of personal protective equipment, oxygen ventilation systems and COVID19 therapies has been highlighted.

\section{INTRODUCTION}

Since February 21, 2020 Italy has been witnessing a massive COVID-19 outbreak and Italian hospitals have been rapidly overcrowded with COVID-19 patients. In keeping with current recommendations of the Italian Ministry of Health, all non-urgent surgeries have been postponed ${ }^{1}$ with a major shift of resources towards pandemic management, profoundly affecting the training of Otorhinolaryngology (ENT) residents ${ }^{2}$. Currently, residency programs face the challenge of establishing the effects of the disruption of training on procedural skills and competency development in order to effectively address training gaps. Moreover, since current information indicates that roughly $10 \%$ of Italian cases have been among health-care workers, the impact of the disease on trainees deserves to be evaluated.

A nationwide survey has therefore been conducted to assess the impact of COVID-19 on ENT residency programs and gain information that could be employed to implement compensative strategies to maintain high-quality standards of training.

\section{MATERIALS AND METHODS}

\section{Study design}

A prospective web-based survey examining the current status of ENT training across Italy during

COVID-19 pandemic was developed through a videoconference meeting by a task force including 2 young otolaryngologist, 2 ENT residents, 1 Chief of Otorhinolaryngology and 1 University Professor (residency program Director) and targeted ENT residents. 


\section{Development and content of the questionnaire}

The survey consisted of a brief introduction to the project followed by 4 sections, which included a total of 53 multiple-choice questions. The following areas of interest were explored: (1) demographic and professional baseline characteristics of the ENT residents, (2) impact of COVID-19 outbreak on the overall practice of Otorhinolaryngology Units and on residents' daily activities, (3) perception of training gaps and proposed solutions (4) aspects related to management of COVID-19 patients, including the use of personal protective equipment (PPE) and feelings about infection risks.

\section{Distribution of questionnaire and collection of data}

The electronic version of the survey was emailed to all Italian ENT residency program directors (31 programs) who were asked to forward the questionnaire to their residents. All included subjects accepted to participate in the Survey through informed consent for the collection and use of data for scientific purposes. The survey was conducted over 15 days from April 15th, 2020 to April 30th, 2020.

\section{Statistical analysis}

The reference population size was 497 , and the confidence level was set at $95 \%$.

Statistical analysis was performed with STATA 13.0 (College Station, TX: StataCorp LP). Continuous variables were reported as median and interquartile range (IQR), and categorical variables were summarized as frequency and percentage.

\section{RESULTS}

A total of 129 out of 497 (26\%) Italian residents from 22 programs out of 31 (71\%) completed the online questionnaire and gave informed consent. Considering a 95\% confidence level, the margin of error (confidence interval) was \pm 7.45 . Participants' demographics and professional data are listed in Table 1 . The great majority of residents $(119,92 \%)$ worked in hospitals that admitted COVID-19 cases, and an even greater percentage $(127,98 \%)$ reported changes in their daily professional activities (Table 2 ). In particular, in $71 \%$ (91) of the cases surgery was limited only to urgent cases, in $23 \%$ (30) the overall volume of activity was reduced without case selection, in 5\% (7) of cases the ENT activity was shut down, and only 1\% (1) reported no changes. Suspension of all surgical procedures was reported by $23(18 \%)$ of responders, while urgent surgeries were still performed in $82 \%$. Swabs to determine COVID-19 infection were not performed in $25 \%$ of cases prior to surgery.

Changes in resident's weekly activities were reported by 127/129 (98\%) of residents. Further details concerning reduction of inpatients and outpatients and surgical procedures are presented in Table 2.

Table 3 summarizes data about training, learning gaps and possible solutions. In particular, $90 \%$ of residents thought that the changes brought by COVID-19 negatively affected the regular course of their residency. Indeed, a minority of ENT residents was directly involved in the response to the pandemic either collaborating to the medical or ventilator care of COVID-19 patients $(25,19 \%)$, or performing tracheostomies $(14,11 \%)$. A similar percentage of responders $(23,18 \%)$ was able to acquire new skills outside of the traditional ENT curriculum (e.g. management of respiratory patients, ventilator care, etc.). Finally, the overall perception of the quality of training by residents, rated from 1 to 10 with a visual-analogue scale (VAS), decreased from a median score of 7 before the outbreak to 4 during the pandemic.

Data concerning specific training on COVID-19, availability of PPE and exposure to the virus are reported in Table 4. In particular, a median score of 5 (VAS 1-10) was attributed to the fear of contracting COVID-19. On the other hand, the reported median level of stress was actually lower during the pandemic 5 (VAS 1-10) than before (6, VAS 1-10).

\section{DISCUSSION}

Roughly one-quarter of Italian ENT residents responded to the questionnaire with a slight prevalence of males (54\%) and with a similar number of residents attending the first 2 years $(67,5 \%)$ compared with those in the 
last 2 years $(62,5 \%)$ of residency. Seventy-one percent of Italian programs (22/31), distributed all over the country, were sampled. The analyzed sample is therefore fairly representative of the Italian ENT residents' population, with an acceptable margin of error $( \pm 7.45)$. The vast majority of residents reported reductions not only in surgical activity, but also in outpatient visits, to an extent that is clearly significantly affecting clinical exposure. Reduction of residents' activities through rotation of small teams to manage urgent cases has been put in place in many residency programs to reduce the risk of infection and preserve a pool of healthy colleagues to respond to hospital's needs ${ }^{2,3}$. Interestingly, at the time of the survey, only a quarter surgical cases were tested for COVID-19, possibly due to the urgent nature of the cases managed during the pandemic. Also, senior colleagues in charge of tutoring residents reduced surgical teaching, further reducing practical learning possibilities. Nonetheless, they were still available for consultation in the majority of cases. While hospital reorganization and changes related to the pandemic can explain the overall reduction of surgical procedures, it is unclear why roughly half of residents reported that surgical teaching was halted altogether in a time period in which some ENT surgeries were still being performed ${ }^{4}$. One explanation might be related to the necessity of speeding up oncologic procedures requiring resection and reconstruction, in order to minimize the utilization of anesthesiologists that were directly involved with the management of COVID-19 patients admitted in intensive care unit departments ${ }^{5}$. However regarding tracheostomy, the most requested ENT procedure during the pandemic, it has been suggested that expert surgeons would guarantee quicker and more effective procedures, with the aim of reducing spread of droplets from the open airway ${ }^{6}$. However, such claims are unsupported by evidence, and it has been demonstrated that tracheostomies performed by supervised residents are by no means inferior to those carried out by senior colleagues ${ }^{7}$. Contrarily to surgical activities, self-study followed an opposite growth trend for $80 \%$ of residents. On the other hand, while inperson lectures were reduced or remained unchanged due to the social distancing precautions, only a minority of residents $(23 \%)$ had access to online lectures. Development of consortia dedicated to residents' education in the US has considerably increased the availability of materials for distance learning and it represents a promising strategy to cope with the current situation, while also laying the foundations of a structured highquality national teaching curriculum ${ }^{8,9}$. Apart from the implementation of online lessons, to compensate for the reduction in clinical exposure, $41 \%$ of residents favored a prolongation of their training or wished to be reassigned to a COVID-free hospital (10\%). Only a small minority saw the necessity of additional theoretical training (4\%), while the majority of questionnaire responders (44\%) advocated an increase in hands-on training as the most fitting solution. However, due to the present biological risk, reduced availability of cadaver specimens may also obstacle the organization of dissection courses.

Still, in spite of the reduction of learning opportunities, roughly $20 \%$ of residents reported that they were able to gain new skills and received training in ventilator and pharmacological treatment of COVID-19. Indeed, due to overall shortage of doctors, some hospitals reallocated residents to the treatment of COVID19 patients. In other cases, residents volunteered to be assigned to the treatment of COVID-19 cases. While training in respiratory patient care is not part of the traditional ENT curriculum, it could prove useful if further spread of the contagion will increase hospital staffing needs or in case of new flares of the epidemic over the next months. Anyhow, more effective measures to increase the availability and the correct use of PPE are needed since $60 \%$ of residents reported inadequate supplies for high-risk procedures and a $5 \%$ infection rate $^{10}$.

\section{CONCLUSIONS}

The survey demonstrates that the COVID-19 outbreak highly impacted ENT residents in all Italian regions. The reduction of activities, above all surgery, had significant impact on residents' training. It is therefore essential to rapidly implement effective solutions to maintain a high training level, especially in light of the uncertain duration of the pandemic and the possibility of future outbreaks. Furthermore, when regular Otorhinolaryngological activities will resume, widespread availability of proper PPE will be essential to prevent contagion among residents and consultants alike.

\section{REFERENCE}

1 Krajewska J., Krajewski W., Zub K., et al. (2020) COVID-19 in otolaryngologist practice: a review of 
current knowledge. Eur. Arch. Oto-Rhino-Laryngology , 1-13.

2 Potts J.R. (2020) Residency and Fellowship Program Accreditation: Effects of the Novel Coronavirus (COVID-19) Pandemic. J. Am. Coll. Surg.

3 Crosby D.L. \& Sharma A. (2020) Insights on Otolaryngology Residency Training during the COVID-19 Pandemic. Otolaryngol. - Head Neck Surg. (United States) , 1-4.

4 Saibene A.M., Allevi F., Biglioli F., et al. (2020) Role and Management of a Head and Neck Department during the COVID-19 Outbreak in Lombardy. Otolaryngol. - Head Neck Surg. (United States), 1-2.

5 Rampinelli V., Mattavelli D., Gualtieri T., et al. (2020) Reshaping Head and Neck reconstruction policy during the COVID-19 pandemic peak: experience in a front-line institution. Auris Nasus Larynx .

6 Pichi B., Mazzola F., Bonsembiante A., et al. (2020) CORONA-steps for tracheotomy in COVID-19 patients: A staff-safe method for airway management. Oral Oncol. 105, 104682.

7 Fiorini F.R., Santoro R., Deganello A., et al. (2015) Is open tracheotomy performed by residents in otorhinolaryngology a safe procedure? A retrospective cohort study. Eur. Arch. Oto-Rhino-Laryngology 272, 1483-1489.

8 Comer B.T., Gupta N., Mowry S.E., et al. (2020) Otolaryngology Education in the Setting of COVID-19: Current and Future Implications. Otolaryngol. Neck Surg. , 019459982092362.

9 Chick R.C., Clifton G.T., Peace K.M., et al. (2020) Using Technology to Maintain the Education of Residents During the COVID-19 Pandemic. J. Surg. Educ.

10 Cai Y., Jiam N.T., Wai K.C., et al. (2020) Otolaryngology Resident Practices and Perceptions in the Initial Phase of the U.S. COVID-19 Pandemic. Laryngoscope .

\section{Hosted file}

table 1.docx available at https://authorea.com/users/321912/articles/451073-impact-of-covid19-outbreak-on-clinical-practice-and-training-of-young-otorhynolaryngologist-a-nationalsurvey

\section{Hosted file}

Table 2.docx available at https://authorea.com/users/321912/articles/451073-impact-of-covid19-outbreak-on-clinical-practice-and-training-of-young-otorhynolaryngologist-a-nationalsurvey

\section{Hosted file}

Table 3.docx available at https://authorea.com/users/321912/articles/451073-impact-of-covid19-outbreak-on-clinical-practice-and-training-of-young-otorhynolaryngologist-a-nationalsurvey

\section{Hosted file}

Table 4.docx available at https://authorea.com/users/321912/articles/451073-impact-of-covid19-outbreak-on-clinical-practice-and-training-of-young-otorhynolaryngologist-a-nationalsurvey 